\title{
Effects of a Personalized Nurse-Led Educational Program for New Patients Receiving Oral Anticoagulant Therapy after Mechanical Heart Valve Prosthesis Implantation on Adherence to Treatment
}

\author{
Rokeia Eltheni, Ph.D., R.N. ${ }^{1}$, Nikolaos Schizas, M.D., M.Sc. ${ }^{1}$, Nektaria Michopanou, Ph.D.(c), R.N. ${ }^{1}$, \\ Georgios Fildissis, Ph.D., M.D.² \\ ${ }^{1}$ Cardiac Surgery Intensive Care Unit, "Evangelismos" General Hospital of Athens; ${ }^{2}$ Faculy of Nursing, School of Healthcare Sciences, National and Kapodistrian \\ University of Athens, Athens, Greece
}

\section{ARTICLE INFO}

Received August 6, 2020

Revised October 15, 2020

Accepted October 18, 2020

Corresponding author

Nektaria Michopanou

Tel 30-6972740214

Fax 30-2132041989

E-mail info@evaggelismos-hosp.gr

ORCID

https://orcid.org/0000-0003-3468-9494
Background: Life-long anticoagulant therapy is mandatory for patients who undergo heart valve replacement with implantation of a mechanical prosthesis. The aim of this study was to investigate the effects of a nurse-led patient educational program concerning oral anticoagulant therapy intake after heart valve replacement surgery on patients' knowledge of important parameters of anticoagulant administration.

Methods: In this single-center study, 200 patients who underwent surgical implantation of a mechanical prosthesis were divided into 2 groups. The control group received the basic education concerning oral anticoagulants, while the intervention group received a personalized educational program.

Results: Personalized education was correlated with a better regulation of therapeutic international normalized ratio (INR) levels and adequate knowledge among patients. Therapeutic levels of INR were achieved in $45 \%$ of the patients during the first month, $71 \%$ in the third month, and $89 \%$ in the sixth month after discharge in the intervention group, compared to $25 \%, 47 \%$, and $76 \%$ in the control group, respectively. Patients' satisfaction with the information was higher in the intervention group than in the control group. The percentage of satisfaction reached $80 \%$ for the intervention group versus $37 \%$ for the patients of the control group.

Conclusion: The implementation of the nurse-led educational programs was associated with improved clinical results and increased adherence to oral anticoagulant treatment.

Keywords: Personalized education, Oral anticoagulant therapy, Mechanical heart valve, Anticoagulation Knowledge Assessment Questionnaire, Patients' information

\section{Introduction}

Life-long anticoagulant therapy is mandatory for patients who undergo heart valve replacement with the implantation of a mechanical prosthesis. Inadequate regulation of the international normalized ratio (INR), partial thromboplastin time, and, to a lesser degree, the activated partial thromboplastin time through oral anticoagulant intake is related to major complications, such as hemorrhagic and thromboembolic events [1]. Non-adherence to the indicated anticoagulant treatment has a major impact on the inci- dence of severe morbidity or even mortality for this group of patients. Patients' level of knowledge regarding drug intake and its parameters is inadequate in general, as studies have shown that the percentage of poorly informed patients may be as high as $61 \%$ [2].

Although most patients understand the significance of anticoagulant treatment after surgery, education on its proper use is frequently based on general instructions, whereas a more personalized therapeutic strategy seems to be more effective and contributes to ameliorating patients' psychological status [3]. Moreover, educational programs 
act as motivation for patients' adherence and are associated with attitude modification and increased self-control [4].

The aim of this study was to investigate the effects of a nurse-led patient educational program about oral anticoagulant therapy intake after heart valve replacement surgery on patients' knowledge of important parameters of anticoagulant administration. The data from this study will contribute to understanding the impact of postoperative personalized education on patients who need life-long anticoagulant treatment.

\section{Methods}

This prospective, quasi-experimental study was conducted between March 2013 and November 2014 at a single center, the Cardiovascular and Thoracic Department of Evaggelismos General Hospital, Athens, Greece. Data were collected from all patients who underwent cardiac surgery with heart valve replacement and implantation of a mechanical prosthesis. The total number of consecutive patients during this period was 273, but 200 (73.3\%) of them fulfilled the criteria for participating in this study.

The inclusion criteria for the study were defined as follows: (1) age more than 18 years old; (2) open surgical procedure with mechanical prosthesis implantation; (3) prescription of life-long oral anticoagulant therapy (acenocoumarol); (4) an oral and written understanding of the Greek language and the ability to speak and write in Greek; and (5) the provision of informed consent.

The exclusion criteria were (1) re-intervention in patients who had undergone heart valve replacement in the past; (2) administration of anticoagulant therapy before surgery, including any vitamin K antagonist; (3) a history of stroke, coagulopathy, or psychiatric disorders; and (4) death inhospital or during the follow-up period.

These patients were divided into 2 groups: the control group, which included 100 patients, and the intervention group, which also contained 100 patients. The control group received the standard information about the benefits of the anticoagulant drug and medication administration. The instructions were given in oral and written form by the surgeon along with the electronic prescription of the drug, according to our hospital's protocol. In the intervention group, a nurse-led educational program for oral anticoagulant treatment after implantation of a mechanical prosthesis through surgery and an educational booklet for such patients were added. The nursing educational program included a verbal 20-minute course on this subject on the fourth, fifth, and sixth postoperative days, during which patients were encouraged to ask questions and express their specific needs. During the course, the patient was alone with the instructor, who was the same for the whole intervention group. The title of the booklet, which was created for the purpose of this study, was "What you should know about anticoagulant therapy following heart valve replacement surgery". The content of this booklet was based on commonly accepted medical practice in this field, reliable sources from the literature, and 2 experts' opinions on this subject. The structure and content of the booklet were explained analytically by the researcher. The researcher gave enough time to the patients for questions and clarifications.

Table 1. Satisfaction of the participants in the study and reasons for lack of satisfaction

\begin{tabular}{|c|c|c|c|c|}
\hline \multirow{2}{*}{ Variable } & \multirow{2}{*}{ Category } & \multicolumn{2}{|c|}{ Group } & \multirow{2}{*}{$p$-value } \\
\hline & & Control & Intervention & \\
\hline \multirow{2}{*}{ Satisfaction with education received } & No & $63(63.0)$ & $20(20.0)$ & $<0.001$ \\
\hline & Yes & $37(37.0)$ & $80(80.0)$ & \\
\hline \multirow[t]{11}{*}{ If not, the reasons for a lack of satisfaction } & More knowledge & $10(10.0)$ & 0 & \\
\hline & More knowledge/instructions about the medicine & $19(19.0)$ & 0 & \\
\hline & More knowledge and time for discussion about the medicine & $1(1.0)$ & $1(1.0)$ & \\
\hline & More knowledge and time for explanations & $1(1.0)$ & 0 & \\
\hline & More information & $12(12.0)$ & 0 & \\
\hline & More information and time for discussion about the medicine & 0 & $1(1.0)$ & \\
\hline & More information and time for explanations & $1(1.0)$ & 0 & \\
\hline & More time for discussion & 0 & $2(2.0)$ & \\
\hline & More time for education & $8(8.0)$ & $16(16.0)$ & \\
\hline & More time for explanations & $9(9.0)$ & 0 & \\
\hline & More time for knowledge and explanations & $1(1.0)$ & 0 & \\
\hline
\end{tabular}

Values are presented as number (\%).

a)By Pearson $\chi^{2}$ test. 
Data collection was performed using a specifically designed form for the collection of patients' demographic and clinical data, an information and instruction form for proper receipt of oral anticoagulants, and a questionnaire concerning patients' level of knowledge on oral anticoagulants, which was given on the first, third, and sixth month of monitoring. Both groups were evaluated using the questionnaire on the level of knowledge and INR measurements 1, 3, and 6 months after discharge from the hospital.

Data were collected through a globally accepted questionnaire (the Anticoagulation Knowledge Assessment Questionnaire) used to evaluate the level of knowledge of the patients in both groups. The questionnaire consisted of 29 questions, with only 1 right answer for each question, and its Greek-language version was previously validated by other researchers with an estimation of internal consistency through the Cronbach $\alpha$ (with values more than 0.7 being considered acceptable). After statistical analysis, the cutoff point indicating a good knowledge of oral anticoag- ulant therapy was defined at 21 right answers.

The study was conducted after written approval of the ethics committee of the Evaggelismos General Hospital (permission ID:13488). Patients provided written informed consent after indicating that they fully understood the obligations and the purposes of the study. The researcher was the instructor of the patients' nurse-led educational program and was the same for all cases. The entire investigation and experimentation process was conducted in accordance with the Declaration of Helsinki and Greek legislation on bioethics. The patients' personal data and rights were protected according to the law. The statistical analysis was performed with IBM SPSS ver. 19.0 (IBM Corp., Armonk, NY, USA), and for the comparison of proportions, the chisquare and Fisher exact tests were used. All reported p-values are 2-tailed and the cutoff for statistical significance was set at $\mathrm{p} \leq 0.05$.

In this study, we also measured participants' satisfaction regarding the education received on their life-long medica-

Table 2. The socio-demographic and preoperative clinical characteristics of the participants

\begin{tabular}{|c|c|c|c|}
\hline \multirow{2}{*}{ Characteristic } & \multicolumn{2}{|c|}{ Group } & \multirow{2}{*}{$\mathrm{p}$-value ${ }^{\mathrm{a})}$} \\
\hline & Control & Intervention & \\
\hline \multicolumn{4}{|l|}{ Socio-demographic characteristics of patients } \\
\hline Age $(y r)$ & $65.0 \pm 11.5$ & $65.4 \pm 11.3$ & 0.804 \\
\hline Sex & & & 0.565 \\
\hline Male & $61(61.0)$ & $57(57.0)$ & \\
\hline Female & $39(39.0)$ & $43(43.0)$ & \\
\hline Body mass index $\left(\mathrm{kg} / \mathrm{m}^{2}\right)$ & $27.2 \pm 4.4$ & $28.1 \pm 4.5$ & 0.154 \\
\hline Educational level & & & 0.532 \\
\hline Primary & $65(65.0)$ & $72(72.0)$ & \\
\hline Secondary & $24(24.0)$ & $18(18.0)$ & \\
\hline Tertiary & $11(11.0)$ & $10(10.0)$ & \\
\hline Monthly income (euro) & & & 0.390 \\
\hline$<500$ & $25.5(25.0)$ & $34(34.0)$ & \\
\hline $500-1,000$ & $53(54.1)$ & $50(50.0)$ & \\
\hline$>1,000$ & $20(20.4)$ & $16(16.0)$ & \\
\hline \multicolumn{4}{|l|}{ Clinical characteristics } \\
\hline Chronic disease & & & 0.514 \\
\hline No & $73(73.0)$ & $77(77.0)$ & \\
\hline Yes & $27(27.0)$ & $23(23.0)$ & \\
\hline Preoperative antiplatelet or anticoagulant treatment (except acenocoumarol) & & & 1.000 \\
\hline No & $67(67.0)$ & $67(67.0)$ & \\
\hline Yes & $33(33.0)$ & $33(33.0)$ & \\
\hline Diabetes mellitus & & & 0.617 \\
\hline No & $75(75.0)$ & $78(78.0)$ & \\
\hline Yes & $25(25.0)$ & $22(22.0)$ & \\
\hline Chronic obstructive pulmonary disease & & & 0.341 \\
\hline No & $81(81.0)$ & $86(86.0)$ & \\
\hline Yes & $19(19.0)$ & $14(14.0)$ & \\
\hline
\end{tabular}

Values are presented as mean \pm standard deviation or number (\%).

a)By Pearson $\chi^{2}$ test. 
tion. The percentage of satisfaction was $80 \%$ in the intervention group, while $37 \%$ of the patients of the control group were satisfied with the education that they received (Table 1). Only half of the unsatisfied patients in the control group reported that the reasons for their dissatisfaction were that they received inadequate information (10\%), combined with poor knowledge and unclear instructions (29\%), followed by other reasons, while the main reason for inconvenience in the intervention group was the need for more time for education (16\%). In order to evaluate patients' satisfaction, we used a form edited by the researchers that the patients filled in to answer whether or not they were satisfied with the method of education and the reasons why.

The basic goal of this research was to evaluate the impact of a nurse-led educational program for patients who require lifelong anticoagulant therapy after heart valve replacement surgery. Our hypothesis was that proper education could eliminate the risks related to oral anticoagulant

Table 3. INR measurements at FU examinations

\begin{tabular}{lccc}
\hline \multirow{2}{*}{ INR levels } & \multicolumn{2}{c}{ Group } & \multirow{2}{*}{ p-value ${ }^{\mathrm{a})}$} \\
\cline { 2 - 3 } & Control & Intervention & \\
\hline 1-mo FU & & & \\
Therapeutic & $25(25.0)$ & $45(45.0)$ & 0.011 \\
Low & $41(41.0)$ & $32(32.0)$ & \\
High & $34(34.0)$ & $23(23.0)$ & \\
3-mo FU & & & \\
Therapeutic & $47(47.0)$ & $71(72.4)$ & 0.001 \\
Low & $17(17.0)$ & $13(13.3)$ & \\
High & $36(36.0)$ & $14(14.3)$ & \\
6-mo FU & $76(76.0)$ & $89(90.8)$ & 0.014 \\
Therapeutic & $7(7.0)$ & $1(1.0)$ & \\
Low & $17(17.0)$ & $8(8.2)$ & \\
High & & & \\
\hline
\end{tabular}

Values are presented as number (\%). The participants were divided into 3 categories according to the achievement of the therapeutic goal.

FU, follow-up; INR, international normalized ratio.

a) By Pearson $\chi^{2}$ test. intake and that nursing guidance could contribute effectively to this effort.

\section{Results}

Both groups in this study had similar socio-demographic and clinical characteristics. More specifically, the patients' mean age was $65.0 \pm 11.5$ years in the control group and $65.4 \pm 11.3$ years in the intervention group. A male sex predominance was detected, and most of the participants (approximately $60 \%$ in both groups) were inhabitants of Greece of African origin, with a monthly income of 5001,000 euros and a primary educational level (Table 2). At the time of discharge from the hospital, the INR levels were found to be normal in $45 \%$ of the patients in the control group and $38 \%$ of patients in the intervention group, while low levels were found in $42 \%$ and $45 \%$ of patients and high levels in $13 \%$ and $14 \%$ of patients, respectively.

According to the follow-up protocol of the study, patients' level of knowledge about oral anticoagulant treatment was assessed with a questionnaire 1, 3, and 6 months after discharge from the hospital, while their adherence to the treatment was checked through measurements of INR at the same time points. The results of the INR measurements are depicted in Table 3, in which the participants are categorized into 3 groups according to the achievement of their therapeutic goals (Table 3).

These findings suggest that the intervention group showed higher adherence to oral anticoagulant therapy at all periods of re-evaluation and that both groups showed improvements over time in the achievement of therapeutic goals.

The variation of INR measurements during follow-up is also worth mentioning (Table 4). Although the average variation was similar in both groups in the first and sixth months, and a statistically significant difference was only found for the third-month evaluation, the variation in the INR levels in the control group was higher. Based on this

Table 4. Variation in INR levels at FU examinations: comparison between the control and intervention group

\begin{tabular}{|c|c|c|c|c|c|c|c|c|}
\hline \multirow{2}{*}{ Group } & \multicolumn{4}{|c|}{ INR } & \multicolumn{3}{|c|}{$p$-value ${ }^{a)}$} & \multirow{2}{*}{$p$-value ${ }^{b}$} \\
\hline & $1 \mathrm{mo}$ & $3 \mathrm{mo}$ & $6 \mathrm{mo}$ & Variation & $1 \mathrm{mo} \mathrm{vs.} 3 \mathrm{mo}$ & $3 \mathrm{mo} \mathrm{vs.} 6 \mathrm{mo}$ & $1 \mathrm{mo}$ vs. $6 \mathrm{mo}$ & \\
\hline Control & $2.92 \pm 0.78$ & $3.09 \pm 0.64$ & $3 \pm 0.33$ & $0.08 \pm 0.73$ & 0.239 & 0.200 & 1.000 & 0.034 \\
\hline Intervention & $2.97 \pm 1.19$ & $2.93 \pm 0.46$ & $3 \pm 0.36$ & $0.03 \pm 1.10$ & 1.000 & 0.500 & 1.000 & - \\
\hline p-value ${ }^{c)}$ & 0.775 & 0.050 & 0.917 & - & & & & \\
\hline
\end{tabular}

Values are presented as mean \pm standard deviation, unless otherwise stated. Differences in the variation from one measurement to the next between the 2 groups.

INR, international normalized ratio; FU, follow-up.

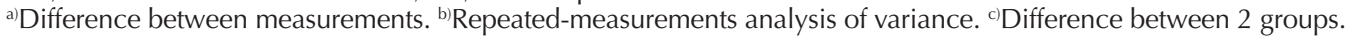


Table 5. Percentage of patients who responded to more than 21 questions correctly

\begin{tabular}{|c|c|c|c|c|c|c|}
\hline \multirow{2}{*}{ Group } & \multicolumn{3}{|c|}{$>21$ correct answers } & \multicolumn{3}{|c|}{$p$-value ${ }^{a)}$} \\
\hline & $1 \mathrm{mo}$ & $3 \mathrm{mo}$ & $6 \mathrm{mo}$ & $1 \mathrm{mo} \mathrm{vs} .3 \mathrm{mo}$ & $3 \mathrm{mo}$ vs. $6 \mathrm{mo}$ & $1 \mathrm{mo} \mathrm{vs} .6 \mathrm{mo}$ \\
\hline Control & $12(12.0)$ & $94(94.0)$ & $99(99.0)$ & $<0.001$ & $<0.001$ & 0.118 \\
\hline Intervention & $95(95.0)$ & $99(99.0)$ & $100(100.0)$ & 0.212 & 0.059 & 1.000 \\
\hline$p$-value $e^{\text {b) }}$ & 0.001 & 0.118 & 1.000 & & & \\
\hline
\end{tabular}

Values are presented as number (\%), unless otherwise stated.

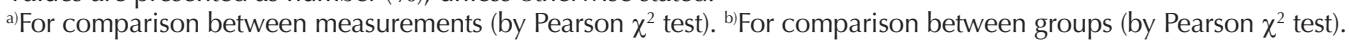

observation, we may speculate that the time in the therapeutic range based on variation in INR levels was worse for the control group than the intervention group.

Patients' level of knowledge about anticoagulant therapy was estimated by the number of correct answers given on a well-known questionnaire, with a cut-off point of 21 correct answers. Table 5 shows the number and the percentage of patients who answered more than 21 questions correctly (Table 5).

From these findings, we conclude that knowledge about oral anticoagulant therapy was clearly better in the intervention group in the first-month evaluation than in the control group $(\mathrm{p}<0.001)$. Nonetheless, the level of knowledge of the control group impressively improved by the third-month evaluation, and by 6 months after surgery, almost all patients were well informed about their treatment.

Furthermore, data were collected regarding the complications related to anticoagulant therapy. Statistically significant differences were detected between the 2 groups at the third-month evaluation, when the incidence of hemorrhagic events was significantly higher in the control group, as shown in Table 6.

\section{Discussion}

The value of oral anticoagulant therapy after heart valve surgery is a matter of primary importance, as ineffective usage is a negative predictor of major complications and death. Additionally, the proper administration of anticoagulant therapy and observation of INR levels require patients to be educated about oral anticoagulant treatment, which contributes substantially to the amelioration of the health services provided and the efficient management of public health resources [5]. Throughout the literature, there is evidence suggesting that adequate education after surgery and ongoing informative programs are effective methods that help reduce the incidence of life-threatening complications $[6,7]$.

Regarding patients' knowledge about the effect of the
Table 6. Three-month incidence of hemorrhagic and thromboembolic episodes in each patient group

\begin{tabular}{cccc}
\hline \multirow{2}{*}{ Outcome } & \multicolumn{2}{c}{ 3-mo incidence } & \\
\cline { 2 - 3 } & $\begin{array}{c}\text { Control group } \\
(\mathrm{n}=100)\end{array}$ & $\begin{array}{c}\text { Intervention } \\
\text { group }(\mathrm{n}=100)\end{array}$ & p-value ${ }^{\mathrm{a})}$ \\
\hline $\begin{array}{c}\text { Hemorrhagic } \\
\text { episodes }\end{array}$ & $14(14.0)$ & $1(1.0)$ & $<0.001$ \\
$\begin{array}{c}\text { Thromboembolic } \\
\text { episodes }\end{array}$ & $4(4.0)$ & $3(3.0)$ & 1.000 \\
\hline
\end{tabular}

Values are presented as number (\%), unless otherwise stated.

a) By Pearson $\chi^{2}$ test.

medication and the reason for its prescription, 2 studies showed that only $40 \%-45 \%$ of patients could answer such questions, while fewer than half of patients (49.2\%) were adequately informed [8,9]. Moreover, a lack of awareness of side effects is a common finding in most patients, even those who take anticoagulant treatment for years [10].

In accordance with our findings, Wang et al. [11], who collected data from a general hospital in Singapore, came to the conclusion that the patients who had participated in an educational program were well informed and found that their INR levels were in the therapeutic range more frequently than those of patients in the control group, who received basic education. Other studies have come to similar conclusions [12,13].

\section{Study limitations}

Although this study was conducted using accepted methods, there are some limitations that should be considered. First of all, this was a single-center experimental study with a relatively low number of patients. The absence of a randomized double-blinded method is also a limitation. Moreover, it should be kept in mind that therapeutic goals for INR levels frequently differ among cardiologists, cardiac surgeons, and departments [14]. 


\section{Conclusions}

The implementation of educational programs was correlated with improved clinical results and increased adherence to oral anticoagulant treatment. A personalized, informative, and educational program could contribute on many levels, such as enhancing patients' motivation and self-control, and promoting an understanding of the need for changes in one's attitude and an early recognition of side effects. Since the main reason for lack of satisfaction in the intervention group was the insufficient duration of education, we think that adding another meeting a few days after discharge might be beneficial. Moreover, the achievement of therapeutic INR levels is crucial in order to avoid life-threatening complications, and in this context, specialized nursing guidance could provide very satisfactory results.

\section{Conflict of interest}

No potential conflict of interest relevant to this article was reported.

\section{ORCID}

Rokeia Eltheni: https://orcid.org/0000-0003-0735-7443

Nikolaos Schizas: https://orcid.org/0000-0002-3523-4881

Nektaria Michopanou: https://orcid.org/0000-0003-3468-9494

Georgios Fildissis: https://orcid.org/0000-0002-1474-4217

\section{References}

1. Emery RW, Emery AM, Raikar GV, Shake JG. Anticoagulation for mechanical heart valves: a role for patient based therapy. J Thromb Thrombolysis 2008;25:18-25.

2. Hu A, Chow CM, Dao D, Errett L, Keith M. Factors influencing patient knowledge of warfarin therapy after mechanical heart valve replacement. J Cardiovasc Nurs 2006;21:169-75.
3. Johnson VD. Promoting behavior change: making healthy choices in wellness and healing choices in illness: use of self-determination theory in nursing practice. Nurs Clin North Am 2007;42:229-41.

4. Ryan P. Integrated theory of health behavior change: background and intervention development. Clin Nurse Spec 2009;23:161-70.

5. Cevik C, Izgi C, Dechyapirom W, Nugent K. Treatment of prosthetic valve thrombosis: rationale for a prospective randomized clinical trial. J Heart Valve Dis 2010;19:161-70.

6. Bagnasco A, Paola F, Angela C, et al. Therapeutic education as a safety promotion tool for patiens on oral anticoagulation therapy. Hell J Nurs Sci 2010;3:11-7.

7. Leiria TL, Lopes RD, Williams JB, Katz JN, Kalil RA, Alexander $\mathrm{JH}$. Antithrombotic therapies in patients with prosthetic heart valves: guidelines translated for the clinician. J Thromb Thrombolysis 2011; 31:514-22.

8. Cheah GM, Martens KH. Coumadin knowledge deficits: do recently hospitalized patients know how to safely manage the medication? Home Healthc Nurse 2003;21:94-100.

9. Shrestha S, Sapkota B, Kumpakha A, Acharya U, Sharma R. Evaluation of patients' knowledge on warfarin in outpatient pharmacy of a tertiary care cardiac center. BMC Res Notes 2015;8:429.

10. Tang EO, Lai CS, Lee KK, Wong RS, Cheng G, Chan TY. Relationship between patients' warfarin knowledge and anticoagulation control. Ann Pharmacother 2003;37:34-9.

11. Wang Y, Kong MC, Lee LH, Ng HJ, Ko Y. Knowledge, satisfaction, and concerns regarding warfarin therapy and their association with warfarin adherence and anticoagulation control. Thromb Res 2014; 133:550-4

12. White HD, Gruber M, Feyzi J, et al. Comparison of outcomes among patients randomized to warfarin therapy according to anticoagulant control: results from SPORTIF III and V. Arch Intern Med 2007;167: $239-45$.

13. Cook-Campbell J, Sefton M. Discharge teaching about warfarin: patient retention of knowledge. Home Healthc Nurse 2010;28:366-74.

14. Hull RD, Garcia DA. Therapeutic use of warfarin and other vitamin $K$ antagonists [Internet]. Waltham (MA): UpToDate; 2016 [cited 2019 May 5]. Available from: http://www.uptodate.com/contents/ therapeutic-use-of-warfarin-and-othervitamin-k-antagonists? 